\title{
Is Roger Federer more loss averse than Serena Williams?
}

\section{Nejat Anbarci, K. Peren Arin, Cagla Okten \& Christina Zenker}

To cite this article: Nejat Anbarci, K. Peren Arin, Cagla Okten \& Christina Zenker (2017) Is Roger Federer more loss averse than Serena Williams?, Applied Economics, 49:35, 3546-3559, DOI: 10.1080/00036846.2016.1262527

To link to this article: https://doi.org/10.1080/00036846.2016.1262527

曲 Published online: 09 Dec 2016.

Submit your article to this journal

Џll Article views: 425

Q View related articles $\square$

View Crossmark data ¿

Citing articles: 2 View citing articles 5 


\title{
Is Roger Federer more loss averse than Serena Williams?
}

\author{
Nejat Anbarci ${ }^{\mathrm{a}}$, K. Peren Arin ${ }^{\mathrm{b}}$, Cagla Okten ${ }^{\mathrm{c}}$ and Christina Zenker ${ }^{\mathrm{b}}$ \\ aDeakin University, Burwood, Melbourne, Australia; 'ªyed University, Abu Dhabi, United Arab Emirates; 'Bilkent University, Ankara, Turkey
}

ABSTRACT

Using data from the high-stakes 2013 Dubai professional tennis tournament, we find that, compared with a tied score, (i) male players have a higher serve speed and thus exhibit more effort when behind in score, and their serve speeds get less sensitive to losses or gains when score difference gets too large, and (ii) female players do not change their serve speed when behind, while serving slower when ahead. Thus, male players comply more with Prospect Theory exhibiting more loss aversion and reflection effect. Our results are robust to controlling for player fixed effects and characteristics with player random effects.

\section{KEYWORDS}

Uncertainty; gender; loss-aversion; panel-data

JEL CLASSIFICATION D81; C23

\section{Motivation}

With their famous Prospect Theory, Kahneman and Tversky (1979) postulated that economic agents make decisions with respect to a salient reference point and are impacted by losses more than gains 'loss aversion'. In addition, they are risk seeking in losses and risk averse in gains - the 'reflection effect'. In this article, we will examine the performance of very experienced professional male and female tennis players to test for loss aversion and reflection effect in a very competitive high-stakes context.

A large empirical literature suggests that loss aversion exists (e.g. Thaler et al. 1997; Genesove and Mayer 2001; among others). While there is hardly any stand-alone literature on the reflection effect, some important papers on risk-taking behaviour in tournament settings provide some support for that effect nevertheless. Bronars (1986), for instance, finds that leading players in sequential tournaments prefer a low-risk strategy to 'lock in' in their gains, whereas lesser players choose a riskier strategy. Moreover, Nieken and Sliwka (2010) find that risktaking behaviour crucially depends on the correlation between the outcomes of a risky strategy as well as on the size of the potential lead of one of the participants. In spite of the extent of the literature documenting behavioural biases such as loss aversion and reflection effect, however, many scholars including some who have documented behavioural biases in some domains earlier - remain sceptical of the claim that biases persist in markets (e.g. List 2003; Levitt and List 2008; Hart 2005). Critics of the decision bias literature believe that biases are likely to be extinguished by competition, large stakes and experience.

In this article, we first use a theoretical model motivated by the Prospect Theory of Kahneman and Tversky (1979). Using simple Tullock contestsuccess functions, we find that (i) a server will put more effort into his/her serve speed when behind in score than when ahead in score, (ii) a server will put less effort into his/her serve speed when significantly behind in score than when slightly behind in score and, likewise, when significantly ahead in score than slightly ahead in score and finally (iii) overall servers will be more risk averse in the domain of gains than in the domain of losses. Then we test the predictions of this simple theoretical model using novel data from the Dubai Duty Free Tennis Championships in 2013. The data on serve speed was obtained from Hawk-Eye Innovations, which uses a ball-tracking technology to measure serve speed.

Our research approach is similar to that of Pope and Schweitzer (2011), who use the performance of professional male golf players to test for loss aversion in a high-stakes context. The authors analyse putts, that is, the final shots players take to complete a hole. They compare the putts golfers attempted to a 'reference point', that is, to par which is the typical 
number of shots golfers take to complete a hole. In other words, they compare the shots attempted for scores other than par to par. The authors find that this reference point of par heavily influences male golfers: when the players are 'under par', that is, players are in the gain domain, they are significantly less accurate than when they attempt otherwise similar putts for par or when they are 'over par'. This shows that male players are loss averse - they invest more focus when putting for par compared with under par to avoid encoding a loss.

In this article, we extend Pope and Schweitzer's paper. More than applying it to tennis data, we contribute to the literature in four different ways. First, we have sufficiently large data for both males and females, and hence we can investigate gender differences in loss aversion. Second, the special nature of tennis allows us to investigate the 'timing' of loss aversion since we can examine behavioural responses to differences in point score, game score and set score. Third, our data on serve speed is a very accurate measure of effort and, therefore, of loss aversion, as the use of Hawk-Eye Technology enables us to obtain precise measures of serve speed. Finally, while accuracy of putts only measures an outcome, serve speed measures the player's input intensity especially given the fact that the serve is the only shot in tennis over which a player has full control.

Consequently, our article is conducive to make an important contribution to this literature by documenting loss aversion as well as reflection effect in a very competitive field setting, with large stakes, with very experienced male and female professional agents. In addition, in a sense, our results can also serve as a strong robustness check of those of Pope and Schweitzer that are specific to golf, since tennis and golf are very different in their competitive nature. In golf one competes against the whole field ('open play'), while in tennis one competes against only one opponent/team at a time ('match play'). ${ }^{1}$ However, we are not the first ones to apply loss aversion to tennis. A recent paper by Mallard (2016) studies loss aversion and decision fatigue at the Wimbledon tennis championship

The first step in our analysis what would constitute the natural and well-defined 'reference point' in tennis - as the counterpart of 'par' in golf. It is the 'tied score'. In tennis, players are 'at par' if the game score is tied in a game (e.g. 0-0, 15-15, 30-30, $40-40$, i.e. deuce) or in a set score (e.g. 1-1, 6-6) or after an equal number of sets, for example, 1-1 (and 2-2 if it is a grand slam tournament); players are not at par otherwise, that is, a server is behind in his serving game (e.g. 30-40) or in games in a set after even numbers of games (e.g. 2-4, 1-5, etc.) or in sets (e.g. $0-1$ or $0-2$ and $1-2$ if it is a Grand Slam tournament).

In our empirical analysis, we find that male players have a higher serve speed and thus exhibit more effort when behind in score than when ahead in score compared with when the score is even. Specifically, we find that being behind in set score increases male players' serve speed - and thus effort - in the order of $1.64 \mathrm{mph}$ or one-tenth of a standard deviation. Thus, male players exhibit a more risk seeking behaviour in the loss domain as they increase their serve speed much more when behind than they decrease their serve speed when ahead (loss aversion). In addition, falling far behind in the game score lowers male players' serve speed and thus effort - and so does pulling far ahead in the game score as well; thus, their serve speeds get less sensitive to losses or gains when score difference gets too large (reflection effect), albeit this latter relationship is not fully symmetric since a player serves harder when he is behind than when he is ahead, which too supports loss aversion. These are fully in line with our theoretical results and as predicted by Prospect Theory overall (Kahneman and Tversky 1979).

A female player, on the other hand, does not change her serve speed and thus her effort when behind compared with when the score is tied, while she serves slower when ahead than when the score is tied. Specifically, being ahead in set score decreases female players' serve speed - and thus effort - in the order of $2.65 \mathrm{mph}$ or one-fifth of a standard deviation. Thus, we find that female players are less risk seeking in the gain domain as they decrease their serve speed much more when behind than they increase their serve speed when ahead. Further, falling far behind in the point score lowers serve speed

\footnotetext{
1Open play versus match play can account for different features in these sports. For instance, Laband (1990) compared golf and tennis and showed, among others, that the open play nature of golf tournaments leads to a lack of dominance by one or a few players, whereas in contrast the match play nature of tennis tournaments is conducive to dominance by one or a few players.
} 
for females and so does pulling far ahead in the point score as well. These results too are in line with our theoretical results and thus by Prospect Theory, albeit in a somewhat different way than those of male players and in a less significant way as well.

Our results are robust to controlling for player fixed effects as well as player characteristics in a player random-effects specification. While we find significant evidence consistent with loss aversion theory for both male and female players in this high-stakes tournament setting, we also find significant differences in the way loss aversion manifests itself across genders in that male players exhibit behaviour more consistent with loss aversion than do female players.

The article is structured as follows. Section II provides background for our article, reviewing relevant literature and tennis scoring rules. Section III presents our theoretical model and provides testable implications. Section IV presents data followed by empirical framework. Section V presents and discusses the results. Section VI concludes.

\section{A brief literature review}

As alluded to before, in Prospect Theory, Kahneman and Tversky (1979) proposed a reference-dependent theory of choice in which economic agents value gains differently than they value losses in two key ways. First, economic agents value losses more than they value commensurate gains; that is, the 'value function' is kinked at the reference point with a steeper gradient for losses than for gains (loss aversion). Second, economic agents are risk seeking in losses and risk averse in gains; that is, the utility function is convex in the loss domain and concave in the gain domain (the 'reflection effect'). Loss aversion has been documented in many laboratory settings (e.g. Thaler et al. 1997; Gneezy and Potters 1997) and in several field settings (see Genesove and Mayer 2001; Camerer et al. 1997; Fehr, Goette, and Zehnder 2007; Odean 1998; Mas 2006), though some scholars have found evidence to suggest that experience and large stakes may eliminate decision errors (List 2003, 2004).

Gill and Stone (2010) have theoretically analysed loss aversion in a tournament-type setting and argued that a loss averse subject is disappointed if she provides effort but does not win the prize. The model of Gill and Stone (2010) combines referencedependent preferences as in the Prospect Theory of Kahneman and Tversky (1979) and the endogeneity of agents' reference points as in the theory of reference-dependent preferences ( $\mathrm{K}^{\prime \prime}$ oszegi and Rabin 2006). The loss-averse person may either provide no effort to minimize his disappointment or invest a very high effort in order to reduce the probability of losing. Gill and Stone (2010) therefore provide a testable explanation for the substantial variance in effort provision observed in tournament settings. Eisenkopf and Teyssier (2013) test this explanation in a laboratory setting and find evidence that loss aversion affects behaviour in tournaments by showing that elimination of losses relative to expectations decreases the variance of effort.

Empirical evidence on gender differences in loss aversion yields mixed results. In experimental studies, Rau (2014) finds that females are more loss averse than males in investment decisions while G"achter, Johnson, and Herrmann (2007) do not find any gender differences in loss aversion when subjects are confronted with various gambles. Wang, Rieger, and Hens (2013) find that men are in general less risk averse in gains and less risk seeking in losses than women but the difference is rather small. Most studies find that females are more risk averse in gains (Agnew et al. 2008; Borghans et al. 2009; Byrnes, Miller, and Schafer 1999; Croson and Gneezy 2009; Dohmen et al. 2011; Von Gaudecker, Van Soest, and Wengström 2011; Hartog, Ferrer-i Carbonell, and Jonker 2002; Schubert et al. 1999).

Results are mixed on whether females are more risk seeking in losses, however. Some studies find that females are more risk seeking in losses (Schubert et al. 1999; Fehr-Duda, De Gennaro, and Schubert 2006), while others find that females are more risk averse in losses (Levin, Snyder, and Chapman 1988). On the other hand, Booij, Van Praag, and Van De Kuilen (2010) and Fehr-Duda, De Gennaro, and Schubert (2006) find no gender difference in utility curvature in gains and losses, suggesting the observed differences in risk attitudes may be driven by loss aversion (Booij, Van Praag, and Van De Kuilen 2010; Brooks and Zank 2005; Schmidt and Traub 2002) or probability weighting (Fehr-Duda, De Gennaro, and Schubert 2006). 
Therefore, the gender differences of risk attitude in losses are generally less conclusive, and further investigation is needed to test to what extent such results can be generalized (see Croson and Gneezy 2009; Eckel and Grossman 2008; for summaries of gender difference of risk preference in gains and losses).

Finally, noting that at important points of a professional tennis match both genders use a more conservative (i.e. less aggressive) playing strategy in that the odds of both hitting winners and making unforced errors decrease, Paserman (2010) points to a different gender difference: the probability of making an unforced error relative to hitting a winner falls for women, while it remains constant for men. Paserman dismisses gender differences on risk attitudes as an explanation of this finding, and instead argues (via a simple game-theoretic model) that a shift from a more aggressive to a less aggressive strategy can optimally arise as a response to a change in the intrinsic probabilities of hitting winners or making unforced errors. In other words, if players already know their intrinsic tendencies that at more important points they are more likely to make unforced errors and less likely to hit winners when playing aggressively, they will be able to foresee that and thus choose to revert to a safer playing strategy.

\section{A brief overview of tennis rules}

According to the International Tennis Federation (ITF), a standard game is scored as follows with the server's score being called first: ' 0 ', ' 15 ', '30', '40', 'game', except if each player/team has won three points, the score is 'deuce'. ${ }^{2}$ After 'deuce', the score is 'advantage' for the player/doubles team who wins the next point. If that same player/team also wins the next point, that player/team wins the 'game'; if the opposing player/team wins the next point, the score is again 'deuce'. A player/team needs to win two consecutive points immediately after 'deuce' to win the 'game'. One must win six games to win a set. However, if both players/teams win five games, a player/team needs to win two consecutive games immediately after the 5-5 score or if both players/ teams win six games, the winner of the set is determined by a 'tie-break'. During a tie-break game, points are scored '0', ' 1 ', '2', '3', etc. The first player/team to win 7 points wins the 'tie-break' and thus the 'set', provided that there is a margin of two points over the opponent player/team; thus, if necessary, the tie break shall continue until this margin is achieved. Similarly, one must win two or three in Grand Slams - sets to win a match. As the Dubai tournament is not a Grand Slam tournament, a player who wins two sets wins the match.

Of particular interest to our analysis, each player has two chances to initiate a point, or to 'serve'. The first serve is usually faster with also a lot of pace and/ or spin. If the server misses this first serve - be it that it goes out or hits the net - then he/she has another chance to serve, which is the second serve. Players generally serve slower during the second serve, since, if a player misses both serves, it is called a double fault, which means their opponent automatically wins the point.

\section{Theoretical framework}

Here, we develop a simple Theoretical Framework to examine the influence that loss aversion may have on first- and second-serve speeds when players are ahead or behind in score. (As explained before, similar to golf, there is a well-defined reference point in tennis, which is represented by a tied score.)

Since in tennis one competes against only one opponent/team at a time ('match play'), our model will have to incorporate the head-to-head contest feature of tennis. Unlike in golf where a player has full control over every shot, the only shot in tennis over which a player has full control is the serve, which also happens to be the most important shot (often claimed to be determining the outcome especially in men's tennis). Therefore, the biggest effort would go into the serve especially in terms of the speed of the serve; this also means more risk taking. The returner's effort, too, is important since he/she has to react as quickly as possible to a faster serve with a significant physical and cognitive effort as a point cannot continue without a return that is placed back into the server's court. Thus, there is a hierarchy of effort levels such that for the server the most important effort is in the serve and for the returner the most important effort is in the return.

\footnotetext{
${ }^{2}$ http://www.itftennis.com/officiating/rulebooks/rules-of-tennis.aspx
} 
We first consider the probability of winning a point as a function of server's serve effectiveness, which in turn will be a function of effort of the server. Let $g_{s}\left(e_{s}\right)$ be the serve effectiveness of the server and $e_{s}$ represents the amount of effort exerted by the server. As mentioned above, let the probability of winning a point be a function of server's serve effectiveness, which in turn is a function of effort of the server:

$$
\begin{aligned}
& \operatorname{Pr}_{\mathrm{s}}(\text { win the point while serving) } \\
& \quad=\mathrm{f}_{\mathrm{s}}\left(\mathrm{g}_{\mathrm{s}}\left(\mathrm{e}_{\mathrm{s}}\right), \mathrm{e}_{\mathrm{r}}, \alpha, \beta\right)+\varepsilon=\frac{\mathrm{e}_{\mathrm{s}}^{\alpha}}{\mathrm{e}_{\mathrm{s}}^{\alpha}+\mathrm{e}_{\mathrm{r}}^{\beta}},
\end{aligned}
$$

where $e_{s}$ represents the amount of effort exerted by the server on the serve, $e_{r}$ represents the amount of effort exerted by the returner and $\varepsilon$ is random noise. $\alpha$ and $\beta$ are such that $1>\alpha, \beta>0$ and they depend on who the server is as well as on $z_{s}$ and, $z_{r}$ which represent vectors of player characteristics (e.g. ranking, height, weight).

This functional form is the well-known standard Tullock (1980) contest-success function, which indicates that winning is a probabilistic event but depends on the relative efforts of contestants crucially. Observe that, since $1>\alpha>0>, f_{s}^{\prime}$ with respect to $e_{s}$ is positive and $f_{s}^{\prime \prime}$ with respect to $e_{s}$ negative; that is, additional effort strictly increases the probability of winning a point and that $f_{s}(\cdot)$ is strictly concave in effort.

Note that the level of effort and of risk taking determines the speed of each serve. To incorporate loss aversion, we utilize the value functions for a winning score $(w)$, a losing score $(l)$ and a tied score $(t)$ such that

$$
V(w)=1, V(l)=-\lambda \text { and } V(t)=0,
$$

where, as in Pope and Schweitzer (2011), too, $\lambda>1$ denotes the degree of the player's loss aversion. This implies that the difference in value between winning a service game and a tied score is smaller than the difference in value between a tied score and losing a point. As such, this value function is a simplified version of the value function implied by Prospect Theory, that is, without diminishing sensitivity in gains or losses of the reflection effect (we will consider the reflection effect after Result 1).

There is a cost of effort for the server, $c_{s}\left(e_{s}\right)$ which strictly increases in effort $e_{s}$ with $c_{s}^{\prime}$ with respect to $e_{s}$ is positive and $c_{s}{ }^{\prime \prime}$ with respect to $e_{s}$ is positive as well; that is, additional effort strictly increases the cost of effort and that $c_{s}(\cdot)$ is strictly convex in effort.

Each server's utility is equal to the values placed on winning and losing a point weighted by their probabilities and subtracting the cost of effort. For our purposes of establishing the impact of loss aversion, we only need to compare payoffs of servers when they are ahead or behind. In particular, a serving player derives the following expected utility when he/she has an advantageous score (e.g. 40-30) while serving for the game (or set or match); that is, when it is a game (or set or match) point favouring the server, where $W$ denotes this state ${ }^{3}$ :

$$
\begin{aligned}
U_{s}(W)= & \frac{e_{s}^{\alpha}}{e_{s}^{\alpha}+e_{r}^{\beta}} V(w)+\frac{1-e_{s}^{\alpha}}{e_{s}^{\alpha}+e_{r}^{\beta}} V(t) \\
& -c_{s}\left(e_{s}\right) \\
= & \frac{e_{s}^{\alpha}}{e_{s}^{\alpha}+e_{r}^{\beta}}-c_{s}\left(e_{s}\right) .
\end{aligned}
$$

Likewise, a serving player derives the following expected utility when he/she has a disadvantageous score (e.g. 30-40) while serving for the game (or set or match); that is, when it is a game (or set or match) point favouring the returner, where $L$ denotes this state:

$$
\begin{aligned}
U_{s}(L)= & \frac{e_{s}^{\alpha}}{e_{s}^{\alpha}+e_{r}^{\beta}} V(t)+\frac{1-e_{s}^{\alpha}}{e_{s}^{\alpha}+e_{r}^{\beta}} V(l) \\
& -c_{s}\left(e_{s}\right) \\
= & \left(1-\frac{e_{s}^{\alpha}}{e_{s}^{\alpha}+e_{r}^{\beta}}\right)(-\lambda)-c_{s}\left(e_{s}\right) .
\end{aligned}
$$

Maximizing the utility functions in Equation (3a) and ( $3 b$ ) yields the following first-order conditions (which, interestingly - and despite using a contestsuccess function which was not needed and thus not used in Pope and Schweitzer (2011) - turn out to be identical to those of Pope and Schweitzer (2011)):

\footnotetext{
${ }^{3}$ One can similarly come up with value functions for other scores (e.g. 15-0, 0-15, 15-15, 30-15, 15-30 and 30-30), which would need to involve the probabilities of a winning game given that score ceteris paribus. The analysis that uses only Us (W) at 40-30 and Us (L) at 30-40 will suffice for our purposes for now. Nevertheless, our more general analysis following Result 1 (which will involve the reflection effect) will need payoff levels at all scores.
} 


$$
\begin{array}{ll}
\frac{c_{s}^{\prime}}{f_{s}^{\prime}}=1 & \text { when the state is } W, \\
\frac{c_{s}^{\prime}}{f_{s}^{\prime}}=\lambda & \text { when the state is } L .
\end{array}
$$

These first-order conditions indicate that a server chooses an optimal level of effort, $e_{s}^{*}$, by setting the marginal cost of effort equal to the marginal benefit of effort when serving. When behind in score, the server chooses a higher optimal effort level, which equates the ratio of the marginal cost and benefit of effort to $\lambda$, than when ahead, which equates the ratio of the marginal cost and benefit of effort to 1 . Thus, the first-order conditions imply that a server chooses a higher effort level in the loss domain than he/she does in the gain domain. We then obtain the following result.

RESULT 1: Controlling for individual characteristics, and $z_{s}$ and $z_{r}$ leading to $\alpha$ and $\beta$, a server will put more effort into his/her serve speed when behind in score than when ahead in score.

In (2), we considered simplified, linear value functions that contained a loss aversion parameter, $\lambda$, only. Let $T_{s}$ denote the score of the server (in terms of points or games or sets) and $T_{r}$ denote the score of the returner. Equation (5) below extends value functions to incorporate both a loss aversion parameter, $\lambda$, as before, as well as separate risk preference parameters for the gain and loss domains (i.e. to consider the reflection effect as well): Let $V(w)=\left(T_{s}-T_{r}\right)^{\gamma}$ with $T_{s}>T_{r}, V(l)=-\lambda\left(T_{r}-T_{s}\right)^{\delta}$, with $T_{r}>T_{s}$ and $V(t)=0$, where $1>\delta \geq \gamma>0$ are parameters that allow for 'diminishing sensitivity' in score difference such that incremental gains in $\left(T_{s}-T_{r}\right)$ above the reference point, that is, the tied score, result in progressively smaller utility improvements and, conversely, incremental reductions in $\left(T_{s}-T_{r}\right)$, which are below the tied score result in progressively smaller declines in utility. In addition, also let $\Delta_{s}=\left(T_{s}-T_{r}\right)$ and $-\Delta_{r}=\left(T_{r}-T_{s}\right)$, where $\Delta_{s}=-\Delta_{r}=\Delta$ if and only if $T_{s}-T_{r}=-\left(T_{r}-T_{s}\right)$.

Then, we will have

$$
\text { (i) } \begin{aligned}
V(w) & =\left(\Delta_{s}\right)^{\gamma}, \text { (ii) } V(l) \\
& =-\lambda\left(-\Delta_{s}\right)^{\delta} \text { and (iii) } V(t)=0 .
\end{aligned}
$$

The curvature of these utility functions induces a server to exert less effort when he/she is much more ahead (e.g. $40-0$ in his/her serve game or $4-0$ in games) than when he/she is slightly ahead (e.g. 40-30 in his/her serve game or 4-3), and less effort when he/she is much more behind (e.g. 0-40 in his/ her serve game or 0-4 in games) than he/she when is slightly behind (e.g. 30-40 in his/her serve game or 3-4 in games).

Maximizing the utility functions in Equation (3a) and (3b) based on Equation (5) will take risk aversion coefficients into consideration (i.e. the effort choice for the serve will depend on those coefficients as well) and yields the following first-order conditions

$$
\begin{gathered}
\frac{c_{s}^{\prime}}{f_{s}^{\prime}}=\left(\Delta_{s}\right)^{\gamma} \quad \text { when the state is } W, \\
\frac{c_{s}^{\prime}}{f_{s}^{\prime}}=\lambda\left(\Delta_{s}\right)^{\delta} \quad \text { when the state is } L .
\end{gathered}
$$

Observe that when $\Delta_{s}=\Delta_{r}=\Delta$, the first-order conditions still clearly imply that a server chooses higher effort level in the loss domain than he/she does in the gain domain for the same score differential. In addition, $c_{s}^{\prime} / f_{s}^{\prime}=\left(\Delta_{s}\right)^{\gamma}$ implies that a server will put more effort into his/her serve speed when slightly ahead in score than significantly ahead in score, while $c_{s}^{\prime} / f_{s}^{\prime}=\lambda \cdot\left(\Delta_{s}\right)^{\delta}$ implies a server will put less effort into his/her serve speed when significantly behind in score than when slightly behind in score.

Further, note that, with $\lambda>1$ and $\delta \geq \gamma$, firstorder conditions also allow that a more loss averse server with $\gamma$ and $\delta$ will put more effort into his/her serve in terms of speed at a more disparate losing score than a less loss averse server with $\gamma^{\prime}<\gamma$ and $\delta^{\prime}<\delta$ will at the same or more disparate losing score.

Thus, we have the following result, which essentially states that players' effort levels and thus serve speeds get less sensitive to losses or gains when score difference gets too large:

RESULT 2: Controlling for individual characteristics, and $z_{s}$ and $z_{r}$ leading to $\alpha$ and $\beta$, a server will put less effort into his/her serve speed when significantly behind in score than when slightly behind in score and, likewise, when significantly ahead in score than slightly ahead in score.

As a result of both the loss aversion and the reflection effect (i.e. diminishing sensitivity) components 
of Prospect Theory (i.e. by both $\lambda>1$ and $1>\delta \geq \gamma>0$ ), servers in the domain of gains will choose a more risk averse serve with a given score $\Delta=\left(T_{s}-T_{r}\right)>0$ than servers in the domain of losses facing the opposite score $-\Delta=\left(T_{s}-T_{r}\right)<0$. This leads to our final result:

RESULT 3: Controlling for individual characteristics, and $z_{s}$ and $z_{r}$ leading to $\alpha$ and $\beta$, a server will be more risk averse in his/her serve speed when ahead with a particular score $\Delta$ than when behind with the opposite score $-\Delta$. Thus, overall, servers will be more risk averse in the domain of gains than in the domain of losses.

\section{Data and empirical framework}

The data used in our article consists of 32 matches (19 matches for male and 13 matches for female players, and as such thousands of first and second serves by both genders) of the Dubai Duty Free Tennis Championships in 2013 for which HawkEye Technology was available. Since its inauguration in 1993, the tournament has been hosted in the Dubai Duty Free Tennis Stadium. It is a $\$ 2$ million 'Women's Tennis Association' (WTA) Premier Event, and a $\$ 2$ million 'Association of Tennis Players' (ATP) 500 tournament. The tournament attracts the best players in the world. In 2013, the number 1 players in the world, Novak Djokovic from Serbia and Victoria Azarenka from Belarus were the top seeds in the tournament for males and females respectively. ${ }^{4}$

Our dependent variable, the serve speed, was obtained from Hawk-Eye Innovations, which uses a ball tracking technology to measure it. The HawkEye technology has been used at all ATP, WTA and ITF tournaments since 2002. ${ }^{5}$ During the 2013 Dubai Duty Free Tennis Championships, it recorded all matches played on the centre court. Only serves that were counted 'in' were included in the dataset, simply because the Hawk-Eye Technology does not measure the serve speed for serves that are ruled 'out'. Data was unavailable for two of the female matches (Putintseva versus. Robson and Stosur versus Makarova), although the Hawk-Eye technology was installed for those matches.
Table 1. Variable definitions.

\begin{tabular}{|c|c|}
\hline Variable & Definition \\
\hline Serve Speed & $\begin{array}{l}\text { The serve speed, measured for every serve in the } \\
\text { match, by Hawk-Eye technology, measured in mph }\end{array}$ \\
\hline Round & $\begin{array}{l}\text { The stage of the tournament, } 1 \text { being the lowest } \\
\text { possible value (first round of matches), and } 6 \text { being } \\
\text { the highest possible value (the final) }\end{array}$ \\
\hline $\begin{array}{l}\text { Tie-break } \\
\text { dummy }\end{array}$ & $\begin{array}{l}\text { The dummy variable which takes the value of } 1 \text { if the } \\
\text { serve takes place during a Tie-Break, } 0 \text { otherwise }\end{array}$ \\
\hline $\begin{array}{l}\text { Second serve } \\
\text { dummy }\end{array}$ & $\begin{array}{l}\text { The dummy variable which takes the value of } 1 \text { if the } \\
\text { serve is 'second serve', which implies that the player } \\
\text { made an error during the first serve and this } \\
\text { particular serve is his/her last chance before he/she } \\
\text { is penalized by a point }\end{array}$ \\
\hline Rank & $\begin{array}{l}\text { The ATP or WTA World-Rank of the player, } 1 \text { week } \\
\text { prior to the start of the tournament (obtained from } \\
\text { ATP or WTA website) }\end{array}$ \\
\hline Age & $\begin{array}{l}\text { The age of the player, measured in months, } 1 \text { week } \\
\text { prior to the start of the tournament (obtained from } \\
\text { ATP or WTA website) }\end{array}$ \\
\hline Height & $\begin{array}{l}\text { The height of the players, measured in centimetres } \\
\text { (obtained from ATP or WTA website) }\end{array}$ \\
\hline Weight & The weight of the player, measured in kilograms \\
\hline$D_{1}$ & $\begin{array}{l}\text { Dummy variable that equals } 1 \text { if the set score is tied at } \\
0,0\end{array}$ \\
\hline$D_{2}$ & $\begin{array}{l}\text { Dummy variable that equals } 1 \text { if the set score is } 0,1 \\
\text { where the serving player is behind }\end{array}$ \\
\hline$D_{3}$ & $\begin{array}{l}\text { Dummy variable that equals } 1 \text { if the set score is } 1,0 \\
\text { where the serving player is ahead }\end{array}$ \\
\hline$D_{4}$ & Dummy variable that equals 1 if the set score is 1,1 \\
\hline $\begin{array}{l}\text { Game } \\
\text { difference }\end{array}$ & $\begin{array}{l}\text { The number of games won by the player currently } \\
\text { serving-the number of games won by the receiver } \\
\text { in the current set, prior to the serve }\end{array}$ \\
\hline Point difference & $\begin{array}{l}\text { The number of points won by the player currently } \\
\text { serving-the number of points won by the receiver } \\
\text { in the current set, prior to the serve }\end{array}$ \\
\hline
\end{tabular}

The player characteristics, such as age, height, weight and rank were obtained from ATP and WTA official sites for male and female players, respectively. The age is measured in months, the height is measured in centimetres and the weight is measured in kilograms. The variable definitions are presented in Table 1, while summary statistics for male and female players are presented in Table 2.

Our Theoretical Framework implies that a server will be more risk averse in his/her serve speed when ahead in score than when behind in score. In some specifications, in addition to set difference, we control for game difference and point difference to see whether being ahead or behind in a set or a game has any effect on serve speed.

We next outline the empirical strategy in our baseline specification to test our hypotheses. We estimate the following equation:

$$
S_{i j}=\alpha_{2} D_{2 i j}+\alpha_{3} D_{3 i j}+\alpha_{4} D_{4 i j}+\beta \eta_{i j}+\gamma t_{i j}+\delta \mu_{i}+\varepsilon_{i j},
$$

\footnotetext{
${ }^{4}$ Victoria Azarenka withdrew with injury, making world number 2 Serena Williams from the United States the top seed.
}

${ }^{5}$ For more information, see http://www.hawkeyeinnovations.co.uk/page/sports-officiating/tennis. 
where $S_{i j}$ is the serve speed of player $i$ in serve $j$. Since a player has to win two sets to win a match, there are four possible outcomes during a match that can be represented as $(0,0),(0,1),(1,0)$ and $(1,1)$, where the first number in each bracket indicates a player's own score and the second number is his opponent's score. Hence, we construct four dummy variables based on these four possible outcomes. Dummy variable $D_{1 i j}$ is equal to 1 if set score is $(0,0)$, dummy variable $D_{2 i j}$ is equal to 1 if set score is $(0,1)$, dummy variable $D_{3 i j}$ is equal 1 if set score is $(1,0)$ and dummy variable $D_{4 i j}$ is equal to 1 if set score is $(1,1) . D_{1}$ is the omitted dummy in the regression.

Dummy variable $\eta_{i j}$ indicates whether the serve is the player's second serve, dummy variable $t_{i j}$ indicates whether the serve is the player's tie-breaking serve and $\mu_{i}$ is a player fixed effect. In alternative specifications, we include a set of player characteristics such as age, rank, height and weight of the player and cluster errors at the player level. $\varepsilon_{i j}$ is the random error term with mean zero conditional on explanatory variables. In some specifications, we will control for player characteristics such as age, rank, height and weight and model the player effects as random.

\section{Results}

\section{Descriptive analysis}

Table 2 presents descriptive statistics by differences in sets for male and female players.
Comparing simple averages for males, we fail to reject that average speed when ahead or behind is significantly different than average speed when tied at $(0,0)$ in set score. However, for females, we find that average speed when behind is significantly higher than average speed when tied at $(0,0)$ in a $t$-test. Furthermore, average speed when ahead is significantly lower than average speed when tied at $(0,0)$ in set score. Hence descriptive statistics for female players are consistent with loss aversion theory. Of course, testing the equality of simple averages does not give us the whole picture. We next turn to regression analysis to examine the effect of set score and game score differences on serve speed.

\section{Regression results}

Main Effects. - Table 3 presents results where we control for dummy variables for each possible set score, a second serve dummy variable and a tiebreak dummy variable in a player fixed effect specification. Columns 1 through 3 present results for male players and 4 through 6 for female players.

As we explained in the methodology section, there are four possible set score outcomes during a match that can be represented as $(0,0),(0,1),(1,0)$ and $(1,1)$, where the first number in each bracket indicates the serving player's own score and the second number is his opponent's score. Hence, we construct four dummy variables based on these four possible outcomes. Again, dummy variable $D_{1}$ is equal to 1 if set score is $(0,0)$, dummy variable $D_{2}$ is equal to 1 if set

Table 2. Descriptive statistics by differences in sets.

\begin{tabular}{|c|c|c|c|c|c|c|c|c|c|c|c|c|c|c|c|c|c|c|c|c|}
\hline \multicolumn{21}{|c|}{ Male players } \\
\hline \multirow[b]{2}{*}{ Variables } & \multicolumn{4}{|c|}{$\begin{array}{c}\text { Full sample } \\
\text { (number of obs }=2191 \text { ) }\end{array}$} & \multicolumn{4}{|c|}{$\begin{array}{c}\text { D1 (number of } \\
\text { obs. }=978 \text { ) }\end{array}$} & \multicolumn{4}{|c|}{ D2 number of obs. $=504)$} & \multicolumn{4}{|c|}{$\begin{array}{c}D 3 \text { (number of } \\
\text { obs. }=473 \text { ) }\end{array}$} & \multicolumn{4}{|c|}{$\begin{array}{l}\text { D4, (number of } \\
\text { obs. }=236 \text { ) }\end{array}$} \\
\hline & Mean & Std & Min & $\operatorname{Max}$ & Mean & Std & Min & Max & Mean & Std & Min & $\operatorname{Max}$ & Mean & Std & Min & $\operatorname{Max}$ & Mean & Std & Min & Max \\
\hline Serve Speed & 105.4 & 14.3 & 72 & 134 & 105.1 & 14.5 & 74 & 134 & 106.0 & 14.1 & 74 & 132 & 104.6 & 13.8 & 78 & 132 & 106.9 & 14.8 & 72 & 132 \\
\hline Rank & 35.3 & 50.1 & 1 & 315 & 40.3 & 54.8 & 1 & 315 & 33.9 & 32.3 & 2 & 167 & 28.6 & 58.9 & 1 & 315 & 30.6 & 38.1 & 2 & 128 \\
\hline Age & 351.6 & 29.8 & 308 & 408 & 353.9 & 29.7 & 308 & 408 & 344.6 & 27.1 & 308 & 395 & 352.5 & 30.8 & 308 & 408 & 354.8 & 31.0 & 308 & 393 \\
\hline Height & 187.7 & 6.3 & 178 & 198 & 187.4 & 6.4 & 178 & 198 & 189.2 & 6.6 & 178 & 198 & 187.0 & 5.1 & 178 & 198 & 187.4 & 6.9 & 178 & 198 \\
\hline Weight & 82.8 & 7.6 & 70 & 97 & 82.5 & 7.6 & 70 & 97 & 83.6 & 8.6 & 70 & 97 & 81.4 & 6.0 & 70 & 97 & 85.2 & 7.1 & 73 & 97 \\
\hline \multicolumn{21}{|c|}{ Female players } \\
\hline & \multicolumn{4}{|c|}{$\begin{array}{c}\text { Full sample } \\
\text { (Number of Obs. }=1312 \text { ) }\end{array}$} & \multicolumn{4}{|c|}{$\begin{array}{c}\text { D1 (Number of } \\
\text { Obs. }=618 \text { ) }\end{array}$} & \multicolumn{4}{|c|}{$\begin{array}{c}\text { D2 (Number of } \\
\text { Obs. }=255 \text { ) }\end{array}$} & \multicolumn{4}{|c|}{$\begin{array}{c}\text { D3 (Number of } \\
\text { Obs. }=242 \text { ) }\end{array}$} & \multicolumn{4}{|c|}{$\begin{array}{l}\text { D4 (Number of } \\
\text { Obs. }=197 \text { ) }\end{array}$} \\
\hline Variables & Mean & Std & Min & $\overline{\operatorname{Max}}$ & Mean & Std & Min & $\overline{\text { Max }}$ & Mean & Std & Min & $\overline{\operatorname{Max}}$ & Mean & Std & Min & $\overline{\operatorname{Max}}$ & Mean & Std & Min & Max \\
\hline Serve speed & 85.6 & 12.0 & 54 & 114 & 85.7 & 11.6 & 54 & 114 & 88.1 & 11.9 & 58 & 114 & 81.4 & 11.3 & 54 & 110 & 87.4 & 12.6 & 54 & 114 \\
\hline Rank & 18.5 & 17.7 & 6 & 91 & 19.1 & 18.7 & 6 & 91 & 23.9 & 23.9 & 6 & 91 & 15.4 & 10.1 & 7 & 38 & 13.5 & 7.3 & 7 & 30 \\
\hline Age & 322.4 & 41.1 & 232 & 387 & 323.6 & 40.1 & 232 & 387 & 319.0 & 45.9 & 232 & 383 & 325.2 & 39.7 & 254 & 387 & 319.5 & 39.2 & 254 & 383 \\
\hline Height & 170.4 & 6.2 & 163 & 182 & 170.5 & 6.4 & 163 & 182 & 171.8 & 5.8 & 163 & 178 & 167.7 & 6.1 & 163 & 182 & 171.5 & 5.5 & 164 & 182 \\
\hline Weight & 61.8 & 4.4 & 55 & 74 & 61.7 & 4.2 & 55 & 74 & 62.7 & 4.9 & 57 & 74 & 60.4 & 3.2 & 55 & 70 & 62.9 & 4.7 & 59 & 74 \\
\hline
\end{tabular}


Table 3. Benchmark regressions.

\begin{tabular}{|c|c|c|c|c|c|c|}
\hline & (1) & (2) & (3) & (4) & (5) & (6) \\
\hline & Males & Males & Males & Females & Females & Females \\
\hline$D 2$ & $\begin{array}{l}1.549^{* * *} \\
(3.01)\end{array}$ & $\begin{array}{l}1.639^{* * * *} \\
(3.18)\end{array}$ & $\begin{array}{l}1.635^{* * * *} \\
(3.18)\end{array}$ & $\begin{array}{r}0.709 \\
(1.27)\end{array}$ & $\begin{array}{c}0.675 \\
(1.19)\end{array}$ & $\begin{array}{r}0.757 \\
(1.34)\end{array}$ \\
\hline D3 & $\begin{array}{c}0.681 \\
(1.29)\end{array}$ & $\begin{array}{c}0.626 \\
(1.19)\end{array}$ & $\begin{array}{r}0.625 \\
(1.19)\end{array}$ & $\begin{array}{l}-2.667^{* * *} \\
(-4.60)\end{array}$ & $\begin{array}{l}-2.691^{* * *} \\
(-4.61)\end{array}$ & $\begin{array}{l}-2.653^{* * *} \\
(-4.55)\end{array}$ \\
\hline D4 & $\begin{array}{l}0.055 \\
(0.08)\end{array}$ & $\begin{array}{c}-0.262 \\
(-0.38)\end{array}$ & $\begin{array}{c}-0.255 \\
(0.37)\end{array}$ & $\begin{array}{l}-1.588^{* *} \\
(-2.50)\end{array}$ & $\begin{array}{l}-1.525^{* *} \\
(-2.38)\end{array}$ & $\begin{array}{l}-1.433^{* *} \\
(-2.24)\end{array}$ \\
\hline Game diff. & - & $\begin{array}{l}-0.503^{* * *} \\
(-3.70)\end{array}$ & $\begin{array}{l}-0.500^{* * *} \\
(-3.67)\end{array}$ & - & $\begin{array}{c}0.001 \\
(0.01)\end{array}$ & $\begin{array}{l}-0.005 \\
(-0.04)\end{array}$ \\
\hline Game diff. $^{2}$ & - & $\begin{array}{l}-0.127^{* * *} \\
(-2.76)\end{array}$ & $\begin{array}{l}-0.127^{* * *} \\
(-2.75)\end{array}$ & - & $\begin{array}{c}0.042 \\
(0.88)\end{array}$ & $\begin{array}{c}0.046 \\
(0.97)\end{array}$ \\
\hline Point diff. & - & & $\begin{array}{c}0.011 \\
(0.07)\end{array}$ & - & - & $\begin{array}{l}-0.167 \\
(-1.00)\end{array}$ \\
\hline Point diff ${ }^{2}$ & - & & $\begin{array}{l}-0.023 \\
(-0.26)\end{array}$ & - & - & $\begin{array}{l}0.261^{* * *} \\
(2.72)\end{array}$ \\
\hline Tie-break dummy & $\begin{array}{l}0.037 \\
(0.03)\end{array}$ & $\begin{array}{l}-0.160 \\
(-0.14)\end{array}$ & $\begin{array}{l}-0.134 \\
(-0.12)\end{array}$ & NA & NA & NA \\
\hline Second serve dummy & $\begin{array}{l}-21.598^{* * *} \\
(-57.85)\end{array}$ & $\begin{array}{l}-21.641^{* * *} \\
(-58.08)\end{array}$ & $\begin{array}{l}-21.642^{* * *} \\
(-58.04)\end{array}$ & $\begin{array}{l}-14.584^{* * * *} \\
(-35.19)\end{array}$ & $\begin{array}{l}-14.586^{* * *} \\
(-35.18)\end{array}$ & $\begin{array}{l}-14.593^{\text {**** }} \\
(-35.27)\end{array}$ \\
\hline Constant & $\begin{array}{l}114.023^{* * *} \\
(359.60)\end{array}$ & $\begin{array}{l}114.248^{* * *} \\
(331.99)\end{array}$ & $\begin{array}{l}114.280^{* * *} \\
(311.18)\end{array}$ & $\begin{array}{l}91.696^{* * *} \\
(274.98)\end{array}$ & $\begin{array}{l}91.578^{* * * *} \\
(245.42)\end{array}$ & $\begin{array}{l}91.173^{\text {*** }} \\
(234.96)\end{array}$ \\
\hline Player fixed effects & Yes & Yes & Yes & Yes & Yes & Yes \\
\hline F-Stat. & $627.77^{* * *}$ & $486.31^{* * *}$ & $377.91^{* * *}$ & $311.65^{* * *}$ & $207.70^{* * *}$ & $157.53^{* * *}$ \\
\hline
\end{tabular}

*Significant at $10 \%$ level, ${ }^{* *}$ significant at the $5 \%$ level, ${ }^{* * *}$ significant at the $1 \%$ level.

score is $(0,1)$ and hence the serving player is behind, dummy variable $D_{3}$ is equal to 1 if set score is $(1,0)$ and hence the serving player is ahead and dummy variable is $D_{4}$ is equal to 1 if set score is $(1,1) . D_{1}$ is the omitted dummy variable in the regression.

In column 1, we observe that $D_{2}$ is positive and significant implying that a male player serves faster when behind than when he is tied at $(0,0)$ with his opponent. This result is consistent with loss aversion theory: a player is more risk seeking when he is in the loss domain. Whereas when he is ahead, his speed is not significantly different from when he is tied at $(0,0)$. We also observe that serve speed decreases for the second serve. This clearly indicates that a player is risk averse and hence reduces serve speed when losing a point if a double fault is at stake. We should also emphasize that the set difference is a solid reference point, and is not affected by which player served first.

A sense of being behind or ahead can also occur when a player is behind or ahead in game score within a given set. Game score difference ranges from -5 to 5 . In column 2 , we include game score difference and game score difference square as additional controls to examine how players respond to differences in game score. The coefficients on set score dummy variables remain mostly unchanged when variables for game score are included.
We observe that the coefficient on game score difference is negative and significant. This suggests that a male player's serve speed is faster when behind than when ahead consistent with loss aversion theory and the results in our Theoretical Framework. We then check whether players' serve speeds are indeed less sensitive to losses or gains when game score differences get too large in absolute terms. Hence to control for this effect, we include the square of game score difference in column 2 in addition to game score difference. We observe that both the game-score difference and the squared term is negative and significant. Hence, while serve speed is higher when behind than when ahead, falling far behind in the game score lowers serve speed and so does pulling far ahead in the game score as well. This is fully in line with Result 2 in our Theoretical Framework section. Nevertheless, due to loss aversion, the relationship is not fully symmetric since a player serves harder when he is behind by, say, $\mathrm{z}$ games than when he is ahead by $\mathrm{z}$ games. This asymmetry is fully in line with Results 1 and 3 in our Theoretical Framework section. This asymmetric non-monotonic relationship between game score difference is shown in Figure 1. The $\mathrm{x}$-axis increases with game score difference where positive numbers indicate a server who is ahead in games vis-a-vis the server's opponent. The y-axis reports the serve speed in miles per hour. 


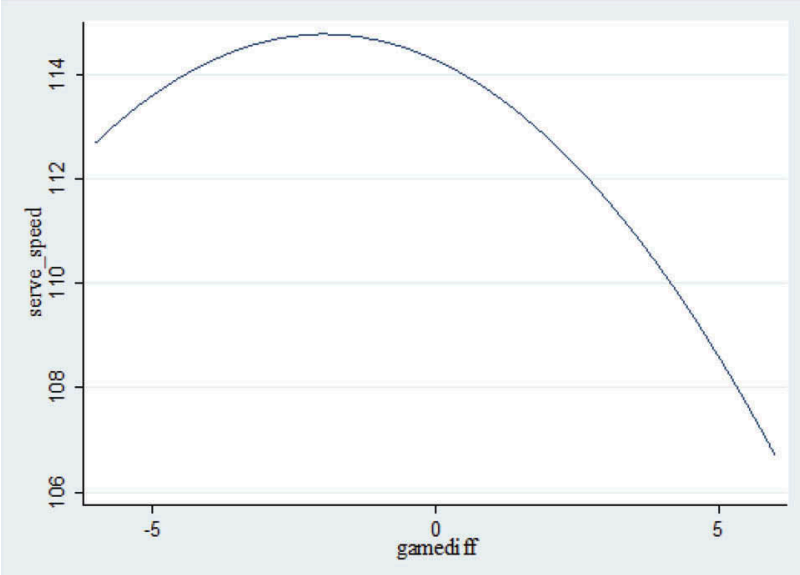

Figure 1. Example of a parametric plot.

In column 3 we also control for point score difference and point score difference square to further examine when exactly behaviour consistent with loss aversion kicks in. We do not find variables for point score to be significant determinants of serve speed. Hence, we find that being behind in set score increases male players' serve speed - and thus effort - in the order of $1.64 \mathrm{mph}$ or one-tenth of a standard deviation.

We next consider results for female players. Column 4 is a fixed effects specification with set score dummy variables, second serve dummy and tie-break dummy as controls. This specification estimated for females is identical to the specification in column 1 that was estimated for males. In this regression, $D_{2}$ is insignificant indicating that a female player does not change her serve speed when behind compared with when she is tied at 0,0 . This result is sharply different from that for male players. On the other hand, we observe that $D_{3}$ is negative and significant compared with the omitted variable $D_{1}$ implying that a female player serves slower when ahead than when she is tied at 0,0 with her opponent. Females are more risk averse in the gain domain but they are not necessarily more risk seeking in the loss domain. Nevertheless, this is still in line with Result 3 in our Theoretical Framework since, overall, female servers too are more risk averse in the domain of gains than in the domain of losses.

It is interesting to note that, female players' serve speed is lower when tied at $(1,1)$ compared with $(0,0)$. It might simply be a conditioning issue or it might be the case that female players decrease serve speed when competitive pressure becomes high. Similar behaviour is observed for female players' second serves. In column 5 , we include game score difference and game score difference square as additional controls. We do not find these variables to be significant for females. Hence, while we find strong evidence for loss aversion for males, results so far are somewhat less conclusive for females. In column 6, we include point score difference and point score difference square as additional controls. The coefficient on point score difference is not significant while the coefficient on point score difference square is positive and significant. The latter is fully in line with Result 2 in our Theoretical Framework. Hence, being ahead in set score decreases female players' serve speed - and thus effort in the order of 2.65 mph or one-fifth of a standard deviation.

Alternative Explanations - We find that male players are more risk seeking in the loss domain and female players are more risk averse in the gain domain. We next consider a number of alternative explanations that might help explain our results.

Differences in player ability - We control for player-level fixed effects to control for unobserved ability of each player. However, in order to examine whether ability and serve speed are correlated, we estimate a linear regression, including player characteristics such as age, rank, height and weight and model player effects as random. Age and rank can be proxies for experience and ability. In these result shown in Table 4, we observe that the statistical significance of coefficients remains similar to the baseline regressions presented in Table 3 . Neither age nor rank is associated with serve speed.

Nervousness - Psychological factors can influence performance (Beilock and Carr 2001; Beilock et al. 2004). Dubai Tennis Tournament is a highstakes competition with large financial consequences, and prior work has found that people often feel nervous or anxious when they face high stakes (McCarthy and Goffin 2004; Beilock 2008; Ariely et al. 2009). Feelings of nervousness can harm performance by disrupting task-focused thinking (Sarason 1984) and by motivating people to make expedient choices to exit their current situation (Brooks and Schweitzer 2011). To account for this possibility, we include the player's rank on the professional tennis tour as proxy. Our results, shown in 3 , are essentially the same as in our baseline-fixed 
Table 4. Controlling for player characteristics.

\begin{tabular}{|c|c|c|c|c|c|c|}
\hline & (1) & (2) & (3) & (4) & (5) & (6) \\
\hline & Males & Males & Males & Females & Females & Females \\
\hline$D 2$ & $\begin{array}{l}1.503^{* * * *} \\
(2.94)\end{array}$ & $\begin{array}{l}1.581^{* * * *} \\
(3.89)\end{array}$ & $\begin{array}{l}1.575^{* * * *} \\
(3.08)\end{array}$ & $\begin{array}{c}0.739 \\
(1.32)\end{array}$ & $\begin{array}{c}0.706 \\
(1.25)\end{array}$ & $\begin{array}{c}0.790 \\
(1.40)\end{array}$ \\
\hline D3 & $\begin{array}{r}0.707 \\
(1.35)\end{array}$ & $\begin{array}{c}0.671 \\
(1.29)\end{array}$ & $\begin{array}{c}0.672 \\
(1.29)\end{array}$ & $\begin{array}{l}-2.641^{* * *} \\
(-4.57)\end{array}$ & $\begin{array}{l}-2.660^{* * *} \\
(-4.56)\end{array}$ & $\begin{array}{l}-2.620^{* * *} \\
(-4.56)\end{array}$ \\
\hline D4 & $\begin{array}{r}0.137 \\
(0.20)\end{array}$ & $\begin{array}{l}-0.163 \\
(-0.24)\end{array}$ & $\begin{array}{l}-0.147 \\
(-0.22)\end{array}$ & $\begin{array}{l}-1.498^{* *} \\
(-2.37)\end{array}$ & $\begin{array}{l}-1.427^{* *} \\
(-2.23)\end{array}$ & $\begin{array}{l}-1.330^{* *} \\
(-2.08)\end{array}$ \\
\hline Game diff. & - & $\begin{array}{l}-0.486^{* * *} \\
(-3.62)\end{array}$ & $\begin{array}{l}-0.484^{* * *} \\
(-3.59)\end{array}$ & - & $\begin{array}{l}0.005 \\
(0.04)\end{array}$ & $\begin{array}{l}-0.001 \\
(-0.01)\end{array}$ \\
\hline 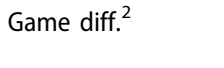 & - & $\begin{array}{l}-0.127^{* * *} \\
(-2.78)\end{array}$ & $\begin{array}{l}-0.127^{* * *} \\
(-2.76)\end{array}$ & - & $\begin{array}{r}0.040 \\
(0.85)\end{array}$ & $\begin{array}{c}0.044 \\
(0.94)\end{array}$ \\
\hline Point diff. & - & - & $\begin{array}{c}0.023 \\
(0.14)\end{array}$ & - & - & $\begin{array}{l}-0.168 \\
(-1.00)\end{array}$ \\
\hline Point diff. ${ }^{2}$ & - & - & $\begin{array}{l}-0.024 \\
(-0.27)\end{array}$ & - & - & $\begin{array}{l}0.264^{* * *} \\
(2.75)\end{array}$ \\
\hline Tie-break dummy & $\begin{array}{l}0.066 \\
(0.06)\end{array}$ & $\begin{array}{l}-0.137 \\
(-0.12)\end{array}$ & $\begin{array}{l}-0.101 \\
(-0.09)\end{array}$ & NA & NA & NA \\
\hline $\begin{array}{l}\text { Second serve } \\
\text { dummy }\end{array}$ & $-21.598^{* * *}$ & $-21.641^{* * *}$ & $-21.643^{* * *}$ & $-14.567^{* * *}$ & $-14.567^{* * *}$ & $-14.573^{* * *}$ \\
\hline & $(-57.91)$ & $(-58.56)$ & $(-58.12)$ & $(-35.15)$ & $(-35.13)$ & $(-35.22)$ \\
\hline Rank & $\begin{array}{l}-0.000 \\
(-0.03)\end{array}$ & $\begin{array}{l}-0.000 \\
(-0.01)\end{array}$ & $\begin{array}{l}-0.000 \\
(-0.00)\end{array}$ & $\begin{array}{c}0.043 \\
(0.49)\end{array}$ & $\begin{array}{r}0.045 \\
(0.53)\end{array}$ & $\begin{array}{c}0.046 \\
(0.56)\end{array}$ \\
\hline Age & $\begin{array}{c}0.023 \\
(0.83)\end{array}$ & $\begin{array}{c}0.024 \\
(0.78)\end{array}$ & $\begin{array}{c}0.024 \\
(0.80)\end{array}$ & $\begin{array}{l}0.003 \\
(0.07)\end{array}$ & $\begin{array}{c}0.003 \\
(0.07)\end{array}$ & $\begin{array}{c}0.003 \\
(0.09)\end{array}$ \\
\hline Height & $\begin{array}{l}0.354^{*} \\
(1.92)\end{array}$ & $\begin{array}{l}0.353^{*} \\
(1.78)\end{array}$ & $\begin{array}{l}0.352^{*} \\
(1.83)\end{array}$ & $\begin{array}{l}0.275 \\
(0.91)\end{array}$ & $\begin{array}{l}0.276 \\
(0.95)\end{array}$ & $\begin{array}{r}0.281 \\
(0.99)\end{array}$ \\
\hline Weight & $\begin{array}{l}0.274^{*} \\
(1.73)\end{array}$ & $\begin{array}{c}0.269 \\
(1.58)\end{array}$ & $\begin{array}{r}0.269 \\
(1.62)\end{array}$ & $\begin{array}{l}0.681^{*} \\
(1.94)\end{array}$ & $\begin{array}{l}0.678 \\
(2.02)\end{array}$ & $\begin{array}{l}0.676^{* *} \\
(2.07)\end{array}$ \\
\hline Constant & $\begin{array}{l}16.679 \\
(0.51)\end{array}$ & $\begin{array}{l}17.480 \\
(0.50)\end{array}$ & $\begin{array}{l}17.528 \\
(0.52)\end{array}$ & $\begin{array}{l}2.154 \\
(0.04)\end{array}$ & $\begin{array}{l}1.968 \\
(0.04)\end{array}$ & $\begin{array}{c}0.619 \\
(0.01)\end{array}$ \\
\hline Player fixed effects & No & No & No & No & No & No \\
\hline Wald-Stat. & $3389.89 * * *$ & $3436.93^{* * *}$ & $3434.27^{* * *}$ & NA & NA & NA \\
\hline$R$-square & 0.61 & 0.61 & 0.61 & 0.47 & 0.47 & 0.48 \\
\hline Number of obs. & 2191 & 2191 & 2191 & 1312 & 1312 & 1312 \\
\hline Estimation method & $\begin{array}{c}\text { Random effects } \\
\text { (GLS) }\end{array}$ & $\begin{array}{c}\text { Random effects } \\
\text { (GLS) }\end{array}$ & $\begin{array}{c}\text { Random effects } \\
\text { (GLS) }\end{array}$ & $\begin{array}{c}\text { Random effects } \\
\text { (GLS) }\end{array}$ & $\begin{array}{c}\text { Random effects } \\
\text { (GLS) }\end{array}$ & $\begin{array}{c}\text { Random effects } \\
\text { (GLS) }\end{array}$ \\
\hline
\end{tabular}

*Significant at $10 \%$ level, ${ }^{*}$ significant at the $5 \%$ level and ${ }^{* * *}$ significant at the $1 \%$ level.

effects specification. Arguably, more experienced players may suffer from less nervousness than less experienced ones. We control for rank as well as age, which is a proxy for experience, in order to test for this possibility and find that rank and age are not significant determinants of serve speed.

Köszegi-Rabin reference points - In our conceptual framework and in our analyses, we have assumed that players make reference-dependent choices adopting in score (par) as their point of reference. In recent theoretical work, $\mathrm{K}^{\prime \prime}$ oszegi and Rabin (2006) suggest that rational expectations might serve as the point of reference for referencedependent choices. Farber (2008) allows reference points to be different across people but treats the income reference points as latent variables (as opposed to assigning reference points based on rational expectations). Professional tennis players may develop expectations for their performance that are different from 'par', that is, from the 'tied score'. For example, average game score in a set or average set score in a match for each player may be the unique reference point for that player. In order to test for this possibility, we have tried a number of different reference points, like the number of points or the number of games won in a match, all of which were insignificant. $^{6}$

Heterogeneity in loss aversion - We next consider heterogeneity across players. We consider individual differences, and we explore the possibility that the most experienced players exhibit less loss aversion than less experienced players. We established that a player serves slower when ahead than when behind in set score. That is, due to loss aversion a player serves faster when behind than when ahead. In order to test how experience plays out in this relationship between serve speed and set score, we include an interaction term of rank with set

\footnotetext{
${ }^{6}$ These results are available upon request.
} 
difference in our baseline specification. If experienced players are less prone to loss aversion, we expect the coefficient on the interaction term to be positive and significant meaning that experience decreases the effect of set score difference on serve speed. In other words, an experienced player is less risk averse (less risk seeking) in the gain domain (loss domain) than an inexperienced player. The inclusion of the aforementioned interaction term, however, did not yield any significant results. ${ }^{7}$

Risk behaviour in tournaments - Looking at risk taking in tournaments, as alluded to before, Bronars (1986) finds that leading players in sequential tournaments prefer a low-risk strategy to a 'lock in' in their gains, whereas their opponents choose a riskier strategy and Nieken and Sliwka (2010) find that risktaking behaviour crucially depends on the correlation between the outcomes of the risky strategy as well as on the size of a potential lead of one of the participants. This strategy, described in Bronars (1986), is indeed analogous to the reflection effect, and the implications of his model appear fully consistent with our results.

\section{Conclusion}

In our theoretical analysis, we have found that (i) a server will put more effort into his/her serve speed when behind in score than when ahead in score, (ii) players' effort levels and thus serve speeds get less sensitive to losses or gains when score difference gets too large and (iii) overall servers will be more risk averse in the domain of gains than in the domain of losses. We have then used serve speed at different points of matches in the high stakes, professional Dubai Tennis Tournament to test our theoretical predictions and whether overall players exhibited the fundamental bias of loss aversion.

Many recent studies have questioned whether the experimental results finding evidence of loss aversion would decline as agents moved into higher stakes or became more experienced. Similar to Pope and Schweitzer (2011)'s results for male players in golf, our results show that in the high stakes, professionalized context of tennis too, experienced professionals, especially male players, exhibit strong behavioural biases. In other words, given that our data comes from professional tennis, which is a very different competitive endeavour than golf (due to golf's open play format versus tennis' match play format, as mentioned before), our results provide evidence that their findings of loss aversion for male golfers in high-stakes settings extend beyond golf. Specifically, we find that professional male tennis players, when behind in score, serve faster than when they are ahead in score.

Furthermore, we control for a number of competing explanations that are consistent with loss averse behaviour, and like Pope and Schweitzer (2011), we find none can accurately explain why serve speed falls as a player's relative score improves. An advantage of our data is that it allows us to test for whether the genders differ in the degree to which they suffer from this behavioural bias. We find that male players are more risk seeking in the loss domain as they increase serve speed when behind in set score while female players are more risk averse in the gain domain since they decrease serve speed when ahead in set score. Hence, although we find evidence for behaviour consistent with loss aversion for both males and females, its manifestation differs significantly between the two sexes.

Our empirical results also indicate that, while male players have a higher serve speed and thus exhibit more effort when behind in score than when ahead in score compared with when the score is even, falling far behind in the game score lowers their serve speed and so does pulling far ahead in the game score as well; thus, their serve speeds get less sensitive to losses or gains when the score difference gets too large. Further, due to loss aversion, this latter relationship is not fully symmetric since a player serves harder when he is behind than when he is ahead. These are fully in line with our theoretical results and as predicted by Prospect Theory overall (Kahneman and Tversky 1979). A female player, on the other hand, does not change her serve speed and thus her effort when behind compared with when the score is tied, while she serves slower when ahead than when the score is tied. Further, falling far behind in the point score lowers serve speed for females and so does

\footnotetext{
${ }^{7}$ These results too are available upon request.
} 
pulling far ahead in the point score as well. These are partially in line with our theoretical results and thus with Prospect Theory. Thus, our results, which are robust to controlling for player fixed effects as well as controlling for player characteristics in a randomeffects specification, show that there are important gender differences in the manifestation of loss aversion in that overall male players exhibit more loss aversion.

Like Pope and Schweitzer (2011), however, we cannot say whether our findings extend to many other different high-stake environments or not. Yet demonstrating this in an alternative competitive setting provides further evidence that agents do systematically suffer from loss aversion and reflection effect. Our study further suggests that it affects both genders, albeit differently.

\section{Acknowledgements}

We would like to thank Peter Dicce and James Smith for providing access to the data, Nick Feltovich, Romain Gauriot, Ilyana Kuziemko, Patrick Nolen, Courtney Nguyen, Devin Pope, Andre Seidel, Christoph Schumacher, Caroline Williams for providing many useful comments and suggestions, Maurice Schweitzer for encouraging our work and Zaid Al-Mahmoud, Blagoj Gegov and Arpad Marinovszki for research assistance.

\section{Disclosure statement}

No potential conflict of interest was reported by the authors.

\section{References}

Agnew, J. R., L. R. Anderson, J. R. Gerlach, and L. R. Szykman. 2008. "Who Chooses Annuities? An Experimental Investigation of the Role of Gender, Framing, and Defaults." American Economic Review 98 (2): 418-422. doi:10.1257/aer.98.2.418.

Ariely, D., U. Gneezy, G. Loewenstein, and N. Mazae. 2009. "Large Stakes and Big Mistakes." Review of Economic Studies 76 (2): 451-469. doi:10.1111/j.1467-937X.2009.00534.x.

Beilock, S. L. 2008. "Math Performance in Stressful Situations." Current Directions in Psychological Science 17 (5): 339-343. doi:10.1111/j.1467-8721.2008.00602.x.

Beilock, S. L., and T. H. Carr. 2001. "More on the Fragility of Performance: Choking under Pressure in Mathematical Problem Solving." Journal of Experimental Psychology: General 130 (4): 701. doi:10.1037/0096-3445.130.4.701.

Beilock, S. L., C. A. Kulp, L. E. Holt, and T. H. Carr. 2004.

"More on the Fragility of Performance: Choking under
Pressure in Mathematical Problem Solving." Journal of Experimental Psychology: General 133 (4): 584-600. doi:10.1037/0096-3445.133.4.584.

Booij, A. S., B. M. S. Van Praag, and G. Van De Kuilen. 2010. “A Parametric Analysis of Prospect Theory's Functionals for the General Population.” Theory and Decision 68 (1-2): 115-148. doi:10.1007/s11238-009-9144-4.

Borghans, L., J. J. Heckman, B. H. H. Golsteyn, and H. Meijers. 2009. "Gender Differences in Risk Aversion and Ambiguity Aversion." Journal of the European Economic Association 7 (2-3): 649-658. doi:10.1162/JEEA.2009.7.2-3.649.

Bronars, S. G. 1986. Strategic Behavior in Tournaments. Austin: University of Texas-Austin.

Brooks, A. W., and M. E. Schweitzer. 2011. "Can Nervous Nelly Negotiate? How Anxiety Causes Negotiators to Make Low First Offers, Exit Early, and Earn Less Profit." Organizational Behavior and Human Decision Processes 115 (1): 43-54. doi:10.1016/j.obhdp.2011.01.008.

Brooks, P., and H. Zank. 2005. "Loss Averse Behavior." Journal of Risk and Uncertainty 31 (3): 301-325. doi:10.1007/s11166-005-5105-7.

Byrnes, J. P., D. C. Miller, and W. D. Schafer. 1999. "Gender Differences in Risk Taking: A Meta-Analysis." Psychological Bulletin 125 (3): 367. doi:10.1037/0033-2909.125.3.367.

Camerer, C., L. Babcock, G. Loewenstein, and R. Thaler. 1997. "Labor Supply of New York City Cabdrivers: One Day at a Time." The Quarterly Journal of Economics 112 (2): 407-441. doi:10.1162/003355397555244.

Croson, R., and U. Gneezy. 2009. "Gender Differences in Preferences.” Journal of Economic Literature 47 (2): 448 474. doi:10.1257/jel.47.2.448.

Dohmen, T., A. Falk, D. Huffman, U. Sunde, J. Schupp, and G. G. Wagner. 2011. "Individual Risk Attitudes: Measurement, Determinants, and Behavioral Consequences." Journal of the European Economic Association 9 (3): 522-550. doi:10.1111/ j.1542-4774.2011.01015.x.

Eckel, C. C., and P. J. Grossman. 2008. "Differences in the Economic Decisions of Men and Women: Experimental Evidence." Handbook of Experimental Economics Results 1: 509-519.

Eisenkopf, G., and S. Teyssier. 2013. "Envy and Loss Aversion in Tournaments." Journal of Economic Psychology $34 \quad$ (1): 240-255. doi:10.1016/j. joep.2012.06.006.

Farber, H. S. 2008. "Reference-Dependent Preferences and Labor Supply: The Case of New York City Taxi Drivers." American Economic Review 98 (3): 1069-1082. doi:10.1257/aer.98.3.1069.

Fehr, E., L. Goette, and C. Zehnder. 2007. The Behavioral Economics of the Labor Market: Central Findings and Their Policy Implications. Mimeo, Boston Federal Reserve Bank.

Fehr-Duda, H., M. De Gennaro, and R. Schubert. 2006. "Gender, Financial Risk, and Probability Weights." Theory and Decision 60 (2- 3): 283-313. doi:10.1007/s11238-005-4590-0.

Gächter, S., E. J. Johnson, and A. Herrmann. 2007. Individual-Level Loss Aversion in Riskless and Risky Choices. IZA Discussion Paper No. 2961. 
Genesove, D., and C. Mayer. 2001. "Loss Aversion and Seller Behavior: Evidence from the Housing Market." WP No. w8143. National Bureau of Economic Research.

Gill, D., and R. Stone. 2010. "Fairness and Desert in Tournaments." Games and Economic Behavior 69 (2): 346-364. doi:10.1016/j.geb.2010.01.002.

Gneezy, U., and J. Potters. 1997. "An Experiment on Risk Taking and Evaluation Periods." The Quarterly Journal of Economics 112 (2): 631-645. doi:10.1162/003355397555217.

Hart, S. 2005. “Adaptive Heuristics.” Econometrica 73 (5): 1401-1430. doi:10.1111/ecta.2005.73.issue-5.

Hartog, J., A. Ferrer-i Carbonell, and N. Jonker. 2002. "Linking Measured Risk Aversion to Individual Characteristics.” Kyklos 55 (1): 3-26. doi:10.1111/kykl.2002.55.issue-1.

Köszegi, B., and M. Rabin. 2006. "A Model of ReferenceDependent Preferences." Quarterly Journal of Economics 121 (4): 1133-1165.

Kahneman, D., and A. Tversky. 1979. "Prospect Theory: An Analysis of Decision under Risk." Econometrica: Journal of the Econometric Society 47 (2): 263-291. doi:10.2307/1914185.

Laband, D. N. 1990. "How the Structure of Competition Influences Performance in Professional Sports: The Case of Tennis and Golf." Sportometrics 133-150. College Station: Texas A\&M University Press.

Levin, I. P., M. A. Snyder, and D. P. Chapman. 1988. "The Interaction of Experiential and Situational Factors and Gender in a Simulated Risky Decision-Making Task.” The Journal of Psychology 122 (2): 173-181. doi:10.1080/ 00223980.1988.9712703.

Levitt, S. D., and J. A. List. 2008. "Economics Homo Economicus Evolves.” Science 319 (5865): 909-910. doi:10.1126/science.1153640.

List, J. A. 2003. "Does Market Experience Eliminate Market Anomalies?” The Quarterly Journal of Economics 118 (1): 41-72. doi:10.1162/00335530360535144.

List, J. A. 2004. "Neoclassical Theory versus Prospect Theory: Evidence from the Marketplace" Econometrica 72 (2): 615-625.

Mallard, G. 2016. "Loss Aversion and Decision Fatigue at the Wimbledon Tennis Championship." International Journal of Behavioural Accounting and Finance 6 (1): 70-91. doi:10.1504/IJBAF.2016.079880.

Mas, A. 2006. "Pay, Reference Points, and Police Performance." WP No. w12202. National Bureau of Economic Research Working Paper 12202.

McCarthy, J., and R. Goffin. 2004. "Measuring Job Interview Anxiety: Beyond Weak Knees and Sweaty Palms."
Personnel Psychology 57 (3): 607-637. doi:10.1111/ peps.2004.57.issue-3.

Nieken, P., and D. Sliwka. 2010. "Risk-Taking Tournaments: Theory and Experimental Evidence." Journal of Economic Psychology 31 (3): 254-268. doi:10.1016/j.joep.2009.03.009.

Odean, T. 1998. "Are Investors Reluctant to Realize Their Losses?" The Journal of Finance 53 (5): 1775-1798. doi:10.1111/0022-1082.00072.

Paserman, D. 2010. Gender Differences in Performance? Evidence from Pro Tennis Players. Boston University, Mimeo.

Pope, D. G., and M. E. Schweitzer. 2011. "Is Tiger Woods Loss Averse? Persistent Bias in the Face of Experience, Competition, and High Stakes." American Economic Review 101 (1): 129-157.

Rau, H. A. 2014. "The Disposition Effect and Loss Aversion: Do Gender Differences Matter?" Economics Letters 123 (1): 33-36. doi:10.1016/j.econlet.2014.0 1.020 .

Sarason, I. G. 1984. "Stress, Anxiety, and Cognitive Interference: Reactions to Tests." Journal of Personality and Social Psychology 46 (4): 929. doi:10.1037/00223514.46.4.929.

Schmidt, U., and S. Traub. 2002. "An Experimental Test of Loss Aversion.” Journal of Risk and Uncertainty 25 (3): 233-249. doi:10.1023/A:1020923921649.

Schubert, R., M. Brown, M. Gysler, and H. W. G. Brachinger. 1999. "Financial Decision-Making: Are Women Really More Risk-Averse?"." American Economic Review 89 (2): 381-385. doi:10.1257/aer.89.2.381.

Thaler, R. H., A. Tversky, D. Kahneman, and A. Schwartz. 1997. "The Effect of Myopia and Loss Aversion on Risk Taking: An Experimental Test." The Quarterly Journal of Economics 112 (2): 647-661. doi:10.1162/003355397555226.

Tullock, G. 1980. Efficient Rent Seeking In Toward a Theory of the Rent-Seeking Society. edited by J. M. Buchanan, R. D. Tollison, and G. Tullock, 97-112. College Station: Texas A\&M University Press.

Von Gaudecker, H.-M., A. Van Soest, and E. Wengstr"Om. 2011. "Heterogeneity in Risky Choice Behavior in a Broad Population.” American Economic Review 101 (2): 664-694. doi:10.1257/aer.101.2.664.

Wang, M., M. O. Rieger, and T. Hens. 2013. How Time Preferences Differ Across Cultures: Evidence from 52 Countries. Mimeo, Norwegian School of Economics. 